\title{
INQUÉRITO MALACOLÓGICO PARA IDENTIFICAR A CÉLULA DE EXPANSÃO DA ESQUISTOSSOMOSE MANSÔNICA NA VILA EMBRATEL, UM BAIRRO DE PERIFERIA DE SÃO LUÍ́S DO MARANHÃO*
}

\author{
MALACOLOGICAL SURVEY TO IDENTIFY THE EXPANSION CELL OF SCHISTOSOMIASIS \\ IN VILA EMBRATEL, A NEIGHBORHOOD IN THE OUTSKIRTS \\ OF SÃO LUÍS - MARANHÃO
}

\author{
ENCUESTA MALACOLÓGICA PARA IDENTIFICAR LA EXPANSIÓN DE LAS CÉLULAS DE \\ LA ESQUISTOSOMIASIS EN VILA EMBRATEL, UN BARRIO EN LAS AFUERAS DE SÃO \\ LUÍS DO MARANHÃO
}

\author{
Dorlam's da Silva Oliveira \\ Gilberth Silva Nunes \\ Renato Juvino Mendes \\ Clícia Rosane Costa França \\ Adalberto Alves Pereira Filho \\ Caio Pavão Tavares \\ Ivone Garros Rosa
}

\begin{abstract}
Resumo: A esquistossomose mansônica é uma parasitose causada pelo Schistosoma mansoni que tem como hospedeiro intermediário caramujos do gênero Biomphalaria. Como forma de fornecer o conhecimento sobre a existência desses caramujos para a comunidade da Vila Embratel, este trabalho teve como objetivo identificar as espécies de planorbídeos, bem como verificar a contaminação por S. mansoni. Os caramujos foram coletados mensalmente na Vila Embratel em dois criadouros. Estes foram identificados por dissecação e analisados com o auxílio de uma lupa estereoscópica para verificar a contaminação por S. mansoni. Foram capturados 634 caramujos do gênero Biomphalaria, sendo que 621 espécimes são $B$. straminea e apenas 13 espécimes são B. glabrata. Foram detectados 6 planorbídeos contaminados pelo parasito da esquistossomose. Verificou-se que não houve uma correlação entre a precipitação pluviométrica acumulada e a abundância de caramujos ( $r=-0,1126$; e o valor de $p=0,8874$ ). Constatou-se que existe uma correlação negativa com o índice de positividade para $S$. mansoni com a temperatura máxima $(r=-0,2378$; e o valor de $p=0,7622)$. Infere-se que este bairro apresenta uma infraestrutura inadequada e caramujos transmissores da esquistossomose, fatores estes essenciais para a propagação desta doença. Palavras-chave: Doença. Caramujo. Esquistossomose
\end{abstract}

\begin{abstract}
Schistosomiasis mansoni is a parasitic disease caused by Schistosoma mansoni whose intermediate host snails of the genus Biomphalaria. As a way to provide knowledge about the existence of these snails to the community of Vila Embratel, this study aimed to identify the species of snails, as well as detect contamination by S. mansoni. The snails were collected monthly in the Vila Embratel in two nurseries. These were identified by dissection and analyzed with the aid of a stereomicroscope to check for contamination by S. mansoni. Were captured 634 snails of the genus Biomphalaria, and 621 specimens are $B$. straminea and only 13 specimens are $B$. glabrata. Was detected 6 snails contaminated by schistosomiasis parasite. It was found that there was a correlation between the cumulative rainfall and abundance of snails $(r=-0,1126$; and the value of $p=0,8874)$. It was found that there is a negative correlation with the rate of positivity for $S$. mansoni with the maximum temperature $(r=-0,2378$; and the value of $p=0,7622)$. It is inferred that this neighborhood has a inadequate infrastructure and snails transmitting schistosomiasis, these essential factors for the spread of this disease.
\end{abstract}

Keywords: Disease. Snail. Schistosomiasis

Resumen: La Esquistosomiasis mansoni es uma parasitosis causada pelo parásito Schistosoma mansoni que tiene como anfitrión intermedio caracoles del género Biomphalaria. Como una manera de proporcionar conocimiento sobre la existencia de estos caracoles a la comunidad de Vila Embratel, este estudio tuvo como objetivo identificar las especies de caracoles, así como detectar la contaminación por S. mansoni. Los caracoles fueron recolectados mensualmente en la Vila Embratel en dos viveros. Estos se identificaron mediante disección y se analizaron con la ayuda de un estereomicroscopio para comprobar la contaminación por S. mansoni. Fueron capturados 634 caracoles del género Biomphalaria, y 621 especímenes son B. straminea y sólo 13 son $B$. glabrata. Fue detectaron 6 caracoles infectados por el parásito esquistosomiasis. Se dedució que no existe una correlación entre la precipitación acumulada y la abundancia de caracoles $(r=-0,1126 ; y$ el valor de $p=0,8874)$. Fué encontrado que existe una correlación negativa con la tasa de

\footnotetext{
Trabalho premiado durante o XXIV Encontro do SEMIC, realizado na UFMA entre os dias 05 a 08 de novembro de 2012.

Aprovado em fevereiro 2013 
positividad para S. mansoni con la temperatura máxima $(r=-0,2378$; y el valor de $p=0,7622)$. Se infiere que este barrio cuenta con una infraestructura inadecuada y caracoles transmisores de la esquistosomiasis, que son factores esenciales para la propagación de esta enfermedad.

Palabras clave: Enfermedad. Caracoles. Esquistosomiasis

\section{INTRODUÇÃO}

A esquistossomose é uma doença endêmica que atinge a maioria dos países, principalmente, países da África, Ásia e América Latina. Apesar dos eficazes programas de controle desta endemia, estima-se que 200 milhões de pessoas estão infectadas e 600 milhões estejam expostas ao risco de contrair esta doença (CIMERMAM; CIMERMAM, 2008). No Brasil, a esquistossomose mansônica ocorre em 19 estados, abrangendo uma área endêmica que vai desde o Maranhão até o Espírito Santo e Minas Gerais, com focos em outros estados. Atualmente cerca de 2.500 .000 a 8.000.000 de brasileiros são portadores da doença. Entretanto, o conhecimento acerca do comportamento epidemiológico dessa parasitose é limitado, existindo estimativas divergentes sobre sua prevalência no país (CANTANHEDE; FERREIRA; MATOS, 2011).

A esquistossomose mansônica é ocasionada pelo trematódeo denominado Schistosoma mansoni. Estes vermes são considerados dioicos, ou seja, com dois sexos separados e apresentam diferentes estágios de desenvolvimento (verme adulto, ovos, miracídios, esporocistos, cercárias e esquistossômulos), cada um deles com as suas características específicas (SOUZA et al., 1998). A transmissão da esquistossomose no Brasil depende da presença de três espécies de caramujo do gênero Biomphalaria: B. glabrata, B. tenagophila, e $B$. straminea. Pelo menos uma das três espécies já foi notificada em 25 das 27 Unidades Federais do país. Esses moluscos são normalmente encontrados em regiões onde há coleções de água doce, como, por exemplo, barragens, áreas de irrigação, rios, lagos, lagoas, brejos e outros (PORDEUS et al., 2008).

A doença ocorre em locais com saneamento inadequado, sendo contraída pela pele ou mucosas que entraram em contato com águas contaminadas com as formas infectantes do parasito. Contudo, para que ocorra a transmissão da esquistossomose, é indispensável à presença do homem na condição de hospedeiro definitivo, que excreta os ovos dos vermes pelas fezes em coleções hídricas, e dos caramujos do gênero Biomphalaria, em condição de hospedeiro intermediário, liberando larvas infectantes do $S$. mansoni em ambientes dulcícolas utilizados pelos seres humanos susceptíveis à doença (vigilância e controle de moluscos).

No Maranhão, a esquistossomose tem sido objeto de pesquisa desde 1920, sendo considerado um problema de Saúde Pública (RAMOS, 2007), apresentando focos em diversas localidades, como a Baixada Ocidental Maranhen se (FERREIRA et al.,1998). Na cidade de São Luís, foram feitos trabalhos de pesquisa sobre a presença de caramujos transmissores da esquistossomose nos bairros de periferia, constatando-se que são áreas bastante propícias para manutenção da doença (RAMOS, 2007).

A Vila Embratel localiza-se na área Itaqui-Bacanga, adjacente à Universidade Federal do Maranhão. Por ser um bairro de periferia de São Luís, foi construído sob nenhum planejamento e encontra-se em uma situação precária no que diz respeito ao saneamento básico.

Nesse contexto, o presente trabalho se propõe à realização de um inquérito malacológico de espécies de caramujos do gênero Biomphalaria, hospedeiros intermediários do parasito causador da esquistossomose, como forma de adoção de medidas profiláticas e vigilância epidemiológica no local de estudo.

\section{MÉTODO}

\section{1 Área de estudo}

O bairro da Vila Embratel (2०34'19.64"S $44^{\circ} 18^{\prime} 28,26^{\prime \prime} \mathrm{W}$ ) encontra-se inserido no eixo do Itaqui-Bacanga, próximo à Universidade Federal do Maranhão, na cidade de São Luís, capital do estado do Maranhão. A escolha do local de estudo foi realizada de acordo com os dados disponibilizados pela Fundação Nacional de Saúde (FUNASA).

\subsection{Seleção dos criadouros}

De acordo com os seguintes critérios: presença de caramujos do gênero Biomphalaria e áreas de riscos pela possibilidade do contato com a água contaminada pela população local, foram selecionados dois criadouros caracterizados como criadouros $A$ e $B$. O criadouro $A$ possui aproximadamente $60 \mathrm{~m}$ de comprimento e está localizado na Rua Bom Futuro. Já o criadouro B apresenta aproximadamente $30 \mathrm{~m}$ de comprimento e está situado na Rua Dezesseis.

\subsection{Coleta de caramujos Biomphalaria}

As coletas dos moluscos foram realizadas mensalmente durante o período de novembro de 2011 a julho de 2012. Foi aplicada a técnica manual para captura de caramujos, utilizando-se luvas, botas de borracha, pinças metálicas e suporte de plástico de aproximadamente 1 $\mathrm{m}$ de comprimento acoplado a uma peneira de metal perfurada (furos em torno de $3 \mathrm{~mm}$ ). Estabeleceu-se em cada coleta 1 hora para a 
captura dos moluscos em cada criadouro selecionado. Os planorbídeos foram acondicionados em recipientes de vidro contendo água desclorada, sendo transferidos para o infectório do Núcleo de Imunologia Básica e Aplicada (NIBA) para posteriormente serem analisados quanto à positividade para $S$. mansoni e identificados em nível de espécie, segundo Paraense (1975).

\subsection{Manutenção dos caramujos}

Os moluscos permaneceram acondicionados no Infectório do NIBA em recipientes de plástico de tamanho razoável, cobertos por uma tela para evitar a sua exposição a insetos e impedir a sua fuga. Os recipientes foram lavados de dois em dois dias, repondo-se a água desclorada. Os caramujos foram alimentados diariamente com folhas de alface (Lactuca sativa) devidamente lavadas com água corrente.

\subsection{Teste de positividade para Schistoso- ma mansoni}

Para análise, utilizaram-se pequenos recipientes de vidro, onde foram adicionados 5 $\mathrm{ml}$ de água desclorada com o auxílio de uma seringa, para cada espécime de caramujo. Estes foram expostos durante 1 hora a uma lâmpada de 60 Watts (SMITHERS; TERRY, 1976). Após isso, cada recipiente foi analisado em uma lupa estereoscópica, para verificar se os moluscos estavam contaminados com a larva do parasito.

\subsection{Identificação dos moluscos}

Primeiramente os planorbídeos foram dissecados por meio da retirada da concha com o auxílio de pinças metálicas. Em seguida, foram fixados em solução de Railliet-Henry, para sua preservação anatômica. Posteriormente, realizou-se a identificação morfológica dos caramujos, analisando as características das conchas e do tubo renal, segundo Paraense (1975).

\subsection{Variáveis ambientais}

Para correlacionar a população de moluscos, assim como a positividade para S. mansoni com as variáveis ambientais, como precipitação pluviométrica e temperatura, utilizou-se dados disponibilizados pelo Núcleo GEO-AMBIENTAL, pertencente à Universidade Estadual do Maranhão (UEMA) que obtém dados diários da PDC instalada na cidade de São Luís ( $2^{\circ}$ 35'S; 440 12'W com $62 \mathrm{~m}$ ).

\subsection{Análise estatística}

A análise estatística dos resultados do trabalho foi realizada por meio do software Statistic 7.0. Para observar possíveis correlações da abundância populacional dos moluscos e a positividade para $S$. mansoni com o volume total de precipitação de cada mês, assim como a temperatura diária de cada mês, foi utilizada a correlação de Pearson (nível de significância $a=0,05)$.

\section{RESULTADO E DISCUSSÃO}

As coletas foram realizadas de novembro de 2011 a julho de 2012. Capturou-se 634 caramujos do gênero Biomphalaria no Bairro da Vila Embratel, sendo 15 obtidos do criadouro A e 619, do criadouro B.

Como pode ser observado na figura 1 , entre os meses de novembro de 2011 e janeiro de 2012, houve um aumento crescente na quantidade de moluscos coletados. Entretanto, ocorreu uma diminuição no mês de fevereiro e uma queda brusca de caramujos no mês de junho. Tal fato pode ter ocorrido devido à área do criadouro marcada para a execução da coleta. O pico de planorbídeos capturados ocorreu no mês de julho. De acordo com o trabalho de Ramos (2007), o período de maior abundância dos caramujos na Vila Embratel se deu durante a estiagem, o que também foi presenciado no presente trabalho. Vale a pena ressaltar que, no criadouro $A$, não foi observado nenhum caramujo desde os meses de dezembro de 2011 a julho de 2012. Isso pode ter ocorrido devido ao aumento no fluxo de correnteza neste criadouro, o que dificulta a instalação dos moluscos no local.

Figura 1 - Abundância de caramujos nos meses de coleta

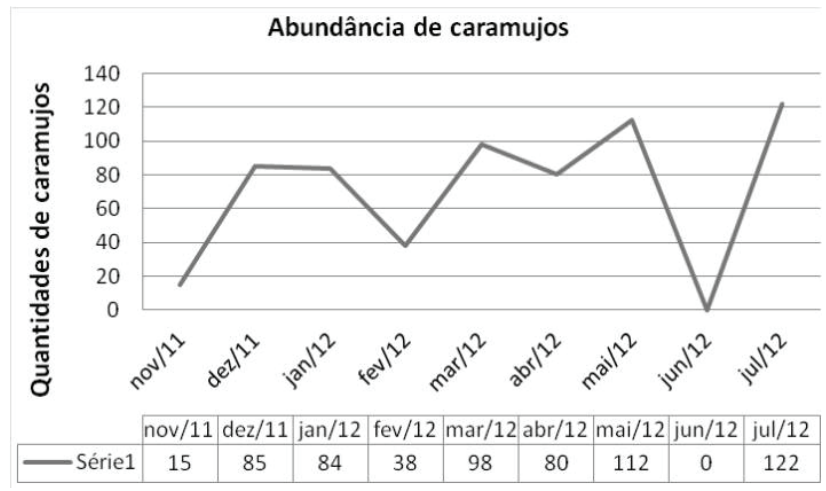

Fonte: Oliveira (2012)

A identificação malacológica demonstrou que o criadouro $A$ apresenta tanto espécies $B$. glabrata, quanto $B$. straminea. Já o criadouro $B$ possui apenas $B$. straminea (Figura 2). Ambas as espécies são vetores naturais para a transmissão da esquistossomose no bairro da Vila Embratel. Verificou-se, no mês de novembro de 2011, por meio da análise de positividade, caramujos B. glabrata contaminados por cercárias. Estes foram coletados no criadouro A, que assinala intensa poluição fecal devido à presença dos dejetos doméstico. 
Figura 2 - Quantificação das espécies coletadas nos criadouros A e B do bairro de periferia da Vila Embratel

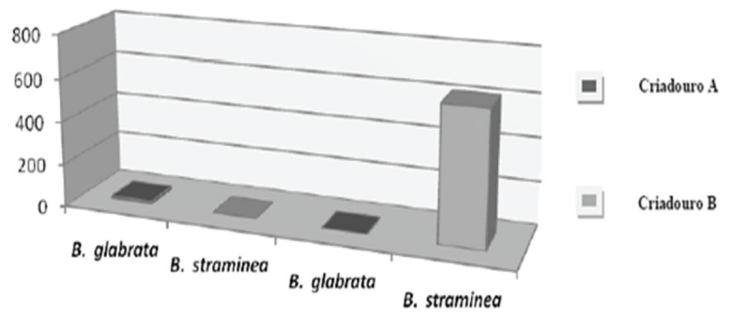

Fonte: Oliveira (2012)

A B. glabrata é considerada de grande importância epidemiológica por conta de sua ampla distribuição geográfica, pelo seu alto nível de infecção e eficácia na transmissão do $S$. mansoni (GUIMARÃES; TAVARES-NETO,2006). A presença de moluscos infectados é um indicador da existência de pessoas contaminadas na comunidade com esquistossomose, uma vez que o homem é o hospedeiro definitivo do trematódeo referido. No criadouro $B$ não foi detectado nenhuma Biomphalaria contaminada, provavelmente pelo fato de as espécies presentes nesse local serem somente $B$. straminea, que possui maior resistência à infecção pelo S. mansoni. Além disso, o criadouro B não possui intenso contato com os dejetos fecais, em comparação com o criadouro A.

Foi constatada uma diminuição na quantidade de caramujos coletados à medida que ocorreu um aumento na precipitação pluviométrica. Contudo, o teste estatístico de Pearson verificou que não há uma correlação entre a precipitação pluviométrica acumulada e a abundância de caramujos $(r=-0,1126$; e 0 valor de $p=0,8874$ ). Este também demonstrou que existe uma correlação negativa com o índice de positividade para $S$. mansoni com a temperatura máxima $(r=-0,2378$; e o valor de $p=0,7622$ ). Para Ramos (2007), a positividade para S. mansoni dos planorbídeos aumenta no período de estiagem devido à alta concentração de miracídios durante esta época, proporcionando, assim, maior probabilidade de infecção dos caramujos e da população que reside nas proximidades dos criadouros.

\section{CONSIDERAÇÕES FINAIS}

O bairro da Vila Embratel apresenta duas espécies de caramujos transmissores da esquistossomose: $B$. straminea e $B$. glabrata. No entanto, somente a B. glabrata, capturada no criadouro A, estava contaminada pelo $S$. mansoni. Por isso, políticas públicas fazem-se necessárias neste bairro para alertar a comunidade sobre esta doença e viabilizar uma infraestrutura adequada, que é de suma importância para evitar sua propagação.

\section{REFERÊNCIAS}

CANTANHEDE, S. P. D.; FERREIRA, A. P.; MATTOS, I. E. Esquistossomose mansônica no Estado do Maranhão, Brasil, 1997-2003. Cadernos de Saúde Pública, vol. 27, n. 4, p. 811-816, 2011.

CIMERMAM, B.; CIMERMAM, S. Parasitologia humana e seus fundamentos gerais. 2.ed. São Paulo: Editora Atheneu, 2008.

FERREIRA, L. A. et al. Forma tumoral encefálica esquistossomótica: apresentação de um caso tratado cirurgicamente. Rev. Sociedade Brasileira de Medicina Tropical, v. 31, n. 1, p. 89-93, 1998.

GUIMARÃES, I. C. S.; TAVARES-NETO, J. Transmissão urbana de esquistossomose em crianças de um bairro de Salvador, Bahia. Rev. Sociedade Brasileira de Medicina Tropical., v. 39, n. 5, p. 451-455, 2006.

PARAENSE, W. L. Estado atual da sistemática dos planorbídeos brasileiros (Mollusca, Gastropoda). Arquivos do Museu Nacional, v. 4, p. 105-128, 1975.

PORDEUS et al. A ocorrência das formas aguda e crônica da esquistossomose mansônica no Brasil no período de 1997 a 2006: uma revisão de literatura. Epidemiologia e Serviços de Saúde, Brasília, v. 17, n. 3, p. 163-175, jul./set. 2008.

RAMOS,C.M. Ocorrência e positividade de Biomphalaria glabrata por Schistosoma mansoni no bairro da Vila Embratel e sua relação como ambiente. 2007. Trabalho de Conclusão de Curso (Graduação em Ciências Biológicas) - Universidade Federal do Maranhão, São Luís, 2007.

SMITHERS, S.R.; TERRY. The imunology of schistosomiasis. Advances in Parasitology. v. 14, p. 399-424, 1976.

SOUZA et al., Moluscos límnicos da microrregião de Belo Horizonte, Minas Gerais, com ênfase nos vetores de parasitose. Revista da Sociedade Brasileira de Medicina Tropical, v. 31, n. 5, p. 449-456, 1998. 